\title{
Mesoscale modelling of bond failure behaviour of ribbed steel bar and concrete interface
}

\author{
Mengjia Liu ${ }^{1}$, Renbo Zhang ${ }^{1}$, Liu $\mathrm{Jin}^{1 *}$ and Xiuli $\mathrm{Du}^{1}$ \\ ${ }^{1}$ The key laboratory of Urban Security and Disaster Engineering of Ministry of Education, Beijing University of Technology, Beijing \\ 100124, China
}

\begin{abstract}
To explore the nonlinear bond behaviour between ribbed bar and concrete, combined with the characteristics of concrete meso-structure and ribbed bar surface characteristics and considering frictional resistance and the mechanical interlocking between rebar and concrete, a meso-scale model is established. Based on the good agreement between the simulation results and experimental results, the failure mechanism of bond between rebar and concrete is discussed, and the distribution characteristics of bond stress of steel bar are analysed. Furthermore, based on the meso numerical analysis method, the influence of friction coefficient between rebar and concrete on the failure mode of concrete and bond stress-slip curve was discussed, and the proportion of friction component in bond strength is obtained.
\end{abstract}

\section{Introduction}

Sufficient bond strength between rebar and surrounding concrete to transfer the stress and coordinated deformation between them is the basis of its good working performance, and it is also the premise for the joint work of rebar and concrete [1-2]. It is of great scientific and engineering significance to study the bond performance and interface behavior between rebar and concrete [3].

A large number of physical tests [3-6] systematically reveal the relevant parameters for interfacial adhesion and provide the basic parameters for the construction of the interface bond-slip nonlinear constitutive model. For example, the bond stress-slip relationship suggested by China's "Specifications for Design of Concrete Structures" [7] is established by referring to the experimental research results of Xu et al. [6]. Wang et al [8] based on $\mathrm{Xu}[6,9]$ simplified deformed steel twodimensional simplified geometric model, deduced and obtained the quantitative relationship of bond strength between steel and concrete interfaces; Melo et al. [3] proposed a polynomial expression of the steel-concrete bond-slip constitutive relation based on fitting analysis of its experimental data. These bond-slip constitutive models provide the basis for the design and numerical simulation of reinforced concrete structures. In fact, the mechanism of the bond between reinforcing steel and concrete is very complex. The existing results are highly dependent on the details of the experiment and the physical tests are difficult to directly observe the process of bond failure between reinforcing steel and concrete and research the bond failure mechanism of the interface. In addition, many finite element methods are applied to study the bond behavior, which often characterize the bond behavior by adding spring elements [10] or cohesive elements [11- 13] Berra et al. [14] simplified the transverse ribs of steel bars and established an axisymmetric contact model. The interfacial bond properties between steel bars and concrete were analyzed.

Those models often have the following problems: 1) the inserted bond element depends on the bond stress-slip constitutive relationship that is measured in the tests. 2) It is difficult to reveal the meso-mechanical failure mechanism of the bond behavior between rebar and concrete. 3) It is difficult to reveal the influence of heterogeneity of concrete on the bond failure behavior. Therefore, a meso-scale numerical model of interface behavior between ribbed steel bar and concrete is established which considers the influence of the friction force and mechanical interlocking. Since the friction component in bond stress between ribbed bar and concrete cannot be measured in the test, a numerical method was used to analyze the influence of the friction coefficient on bond stress-slip curve and the bond failure behavior. Finally the proportion of friction component in bond strength was discussed.

\section{2D meso -scale numerical model for reinforced concrete}

\subsection{Meso-scale computational geometry model}

In order to research the nonlinear bond interaction between rebar and concrete, a finite element numerical simulation is carried out in this paper based on the test research by Ma et al. [15]. In fact, the cracking behavior of concrete caused by rebar slip has a localization effect. Therefore, in order to truly and effectively reveal the bond

*Corresponding author Email: jinliu@bjut.edu.cn 
failure mechanism of the rebar-concrete interface, the heterogeneity of the mesoscopic components of the concrete and the geometric characteristics of the rebar are taken into account in the numerical calculation model.

The measured uniaxial compressive strength was 24.81 MPa. The diameter d of the HRB335 ribbed rebar is $20 \mathrm{~mm}$. The bond length is $100 \mathrm{~mm}$, namely $5 \mathrm{~d}$. The

(a)

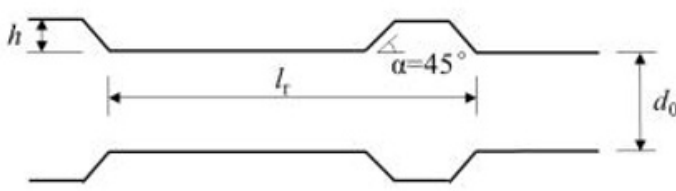

measured yield strength and Young's modulus were 373.64 MPa and 200 GPa respectively. For ribbed bar's the planar geometry and dimension are shown in figure 1a, same as the research [16]. The height of the transverse ribs is $\mathrm{h}=0.07 \mathrm{~d}$, the rib angle $\alpha=45^{\circ}$, the rib spacing $\mathrm{l}=0.6 \mathrm{~d}$, and the steel inner diameter $\mathrm{d} 0=0.96 \mathrm{~d}$ ( $\mathrm{d}$ is the nominal diameter of the steel bar).

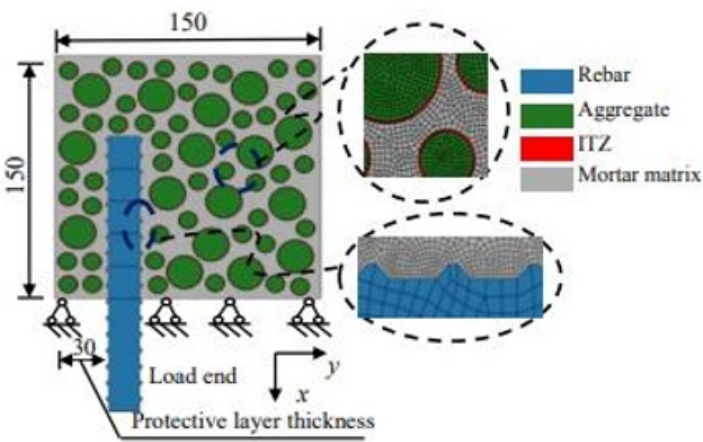

Figure 1. Meso-mechanical numerical model. (a) The geometric size of the rebar; (b) Specimen geometry size and rebar position (unit: $\mathrm{mm}$ ).

The concrete is regarded as a composite composed of three phases consisting of aggregate, mortar matrix, and an interfacial transition zone (ITZs) [17-18]. The aggregate particles are assumed to be round with a volume fraction of $35 \%$. The minimum equivalent particle diameter of $10 \mathrm{~mm}$, and the maximum equivalent particle diameter of $20 \mathrm{~mm}$. The number of the two particles are 46 and 16, respectively. The classic "take-and-place" method [19] was used to place the aggregate particles in the mortar matrix to generate a two-dimensional mesoscopic concrete model, and the thin layer around the aggregate was set as the interface transition zone (the thickness is $0.5 \mathrm{~mm}$ ). The finite element mesh is projected onto the model, and then the element type (such as: aggregate, mortar matrix, and ITZ element) is determined according to the position of each phase component in the mesh, then their material characteristics are assigned according to the element type.

\section{2 rebar-concrete interaction}

In order to simulate the bond behaviour between rebar and concrete, the interaction between rebar and concrete needs to be set. In fact, the bond effect between ribbed steel bars and concrete is composed of three parts: cementing force, friction resistance and mechanical interaction. Relevant tests [16] measured the cementing strength between rebar and concrete in the range of $0.4 \sim 0.8 \mathrm{MPa}$ and it only exists in the non-slipped local area, so it was neglected in present study.

With regard to the contact problem of the mechanical interaction between rebar and concrete, the surface to surface (i.e. master and slave surfaces) contact method was utilized. The "hard contact" is set in normal direction (i.e. non-invasive conditions: the contact pressure that can be transmitted between the contact surfaces is unlimited. when the contact pressure becomes negative or zero, it means that the two contact surfaces are separated). The tangential action is simulated by a penalty method. Coulomb friction is used and the friction coefficient is set to 0.3 [16]. By defining the interaction relationship between the rebar and concrete, the normal pressure and friction force on the transverse ribs of the rebar and the concrete are transmitted to achieve the bond effect between the ribbed rebar and the concrete.

\subsection{Constitutive model and mechanical parameters}

The ideal elastic-plastic constitutive relation was used to describe rebar's mechanical behavior. The elasticity model is adopted for the aggregate [20]; the mechanical behavior of the mortar matrix and interfacial transition zone are described by the plastic damage model proposed by Lee and Fenves [21].

It should be noted that, in order to reduce the effect of mesh size on the numerical results, same with research [20], the fracturing energy-displacement curve is used in the concrete constitutive softening stage (after the peak stress), instead of a stress-strain full curve. The mesoscopic components and the main mechanical parameters of the materials are shown in Table 1.

Table1. The mechanical parameters of concrete meso-components and rebar.

\begin{tabular}{lcccc}
\multicolumn{1}{c}{ Mechanical parameters } & Aggregate & Mortar & ITZ & Rebar \\
\hline Compressive strength (MPa) & & $24^{*}$ & $19.8^{\wedge}$ & - \\
Tensile strength (MPa) & & $2.4^{*}$ & $2^{\wedge}$ & - \\
Elastic modulus(GPa) & $70^{*}$ & $28.3^{*}$ & $22.4^{\wedge}$ & $200^{*}$ \\
Poisson's ratio & 0.2 & 0.2 & 0.2 & $0.3^{*}$ \\
Yield Strength (MPa) & & - & - & $373.6^{*}$ \\
\hline
\end{tabular}

Note: data with “*” are measured by experimental values [15], “^” are repeated trial calculations, the other data is the default. 


\subsection{Loading and boundary conditions}

The concrete surface at the rebar loading direction is the fixed end; the forced displacement which is loaded on the right end of the rebar; the rest surfaces' boundary was set free.

\section{Numerical analysis model verification}

The figure $2 \mathrm{a}-2 \mathrm{~b}$ shows the distribution of bond stress along the bonded length (from the free end to the load end) for different load levels (including the test results and meso-scale simulation results). The bond stress $\tau$ between reinforcing steel and concrete along the anchorage length of the steel is

$$
\tau=A_{s} \mathrm{~d} \sigma_{s}(\pi d \mathrm{~d} x)^{-1}=d \mathrm{~d} \sigma_{s}(4 \mathrm{~d} x)^{-1}
$$

In which, $\mathrm{d} \sigma_{s}$ is the change value of the steel bar stress on the anchorage length $\mathrm{d} x ; A_{s}$ is the bar cross-sectional area; $d$ is the diameter of rebar.

The bond stress increases with the increase of the load level which reaches a maximum approach the free end $(x$
$=0.8 l_{a}$, where $l_{a}$ is bonded length, where $x$ is the distance to the load end of rebar) and then sharply decreases to zero at the free end. In general, the distribution of the bond stress along the bonded length of the rebar simulated by the meso-scale numerical model can agree well with the test's result, which verifies the feasibility and accuracy of the proposed meso-scale numerical simulation method. The figure $2 \mathrm{c}$ shows the bond stress-slip curves of test and simulation result. It can be seen from figure $2 \mathrm{c}$ that the rising section and bond strength of the simulated bond stress-slip curve are all in good agreement with the tested ones. In addition, it can be found that the descending segments obtained from the simulation of the macro model and the mesoscopic model are different from the experimental curves. This difference is mainly attributed to the discreteness and randomness of numerical simulation results, including the distribution of aggregates at the interface and initial defects. In spite of this, the meso-scale simulation results can reveal the bond behavior and failure mechanism of the rebar-concrete interface well.

(a)
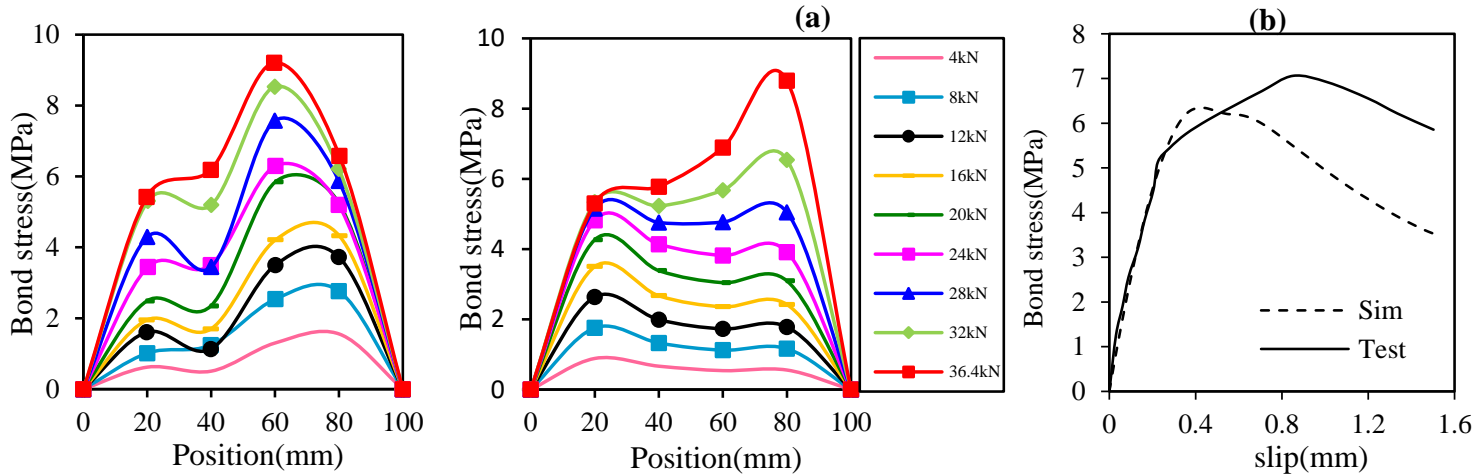

Figure 2. The distribution of bond stress along the bonded length and with the slip. (a) Experiment result ${ }^{[15]}$; (b) Mesoscopic simulation result; (c) the bond stress-slip curves.

\section{Cracking process of the concrete specimen}

indicates the damage index (' 0 ' means no damage, ' 1 ' means complete destruction) and $s$ is the displacement of the load end. It can be seen in figure 3 that the damage region develops along the weak zones (e.g. the interfacial transition zone) in the heterogeneous concretes. The

In order to study the failure mechanism of concrete between ribs, the damage process of the intercostal concrete are showed in figure 3 , in which DAMAGE damage region's develop path is affected by the particle size, position and distribution form.

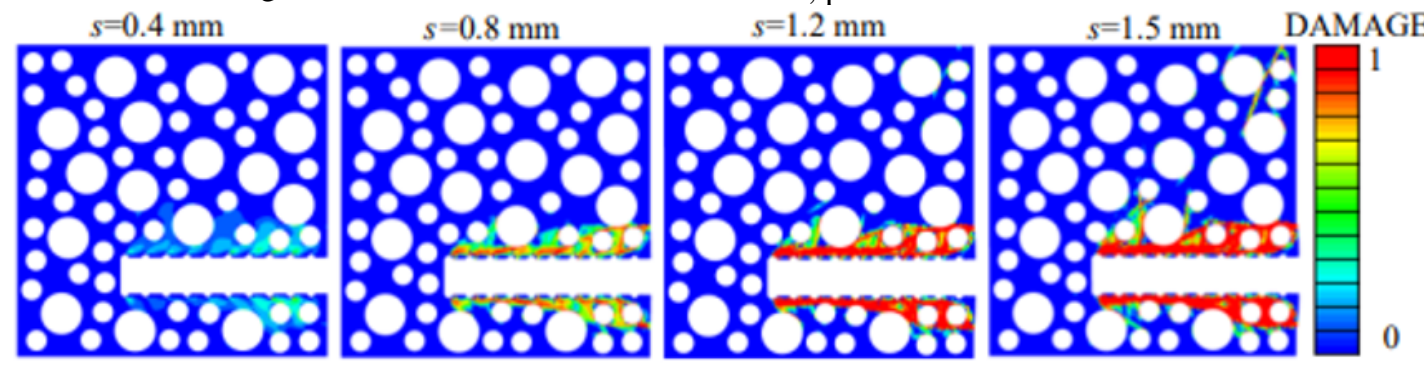

Figure 3. The damage process of the intercostal concrete.

At the initial stage of loading, the concrete damage is distributed evenly along the bond zone, and the rebar's back of the transverse ribs is detached from the concrete, which is the actual delamination crack. The delamination crack continuously develops oblique at the top of the rib, and the slippage of rebar increases at this time. There is a wedge-shaped stacking of the crushed concrete in front of the rebar's ribs, and all the intercostal concrete shear to form a new sliding friction surface.

\section{The influence of friction coefficient}

Since the friction component in bond stress between ribbed bar and concrete cannot be measured in the test, in order to study the proportion of the friction force to the bond strength, the influence of the friction coefficient between the rebar and concrete was studied. 
From figure 4, one can see the effect of friction coefficient on bond stress-slip curve. The selected friction coefficients $\mu$ are $0,0.15,0.3,0.45,0.6$, and 0.75 , respectively. From figure 4, it can be seen that with the friction coefficient increases, the bond strength increases, but when the friction coefficient is greater than 0.3 , the bond strength changes little (when the friction coefficient bigger than 0.3 , the fitting curve's slope is approximately equal to 0 ). The friction coefficients have little effect on the slope of the rising section of the bond slip curve, which is reflected in the almost coincident slope of the rising section of the curve. The simulation results in figure $4 \mathrm{~b}$

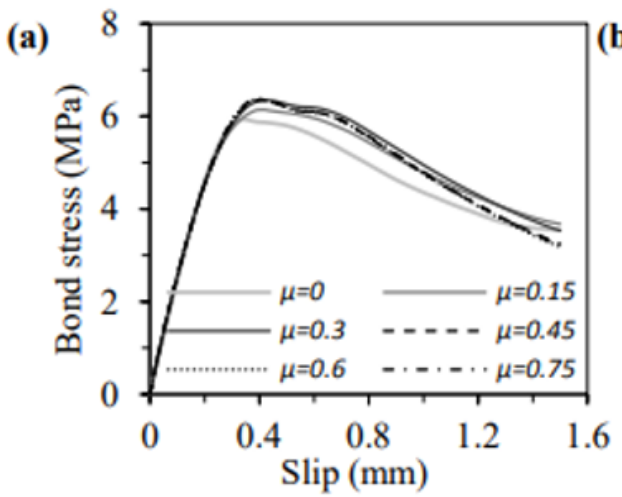

(b)

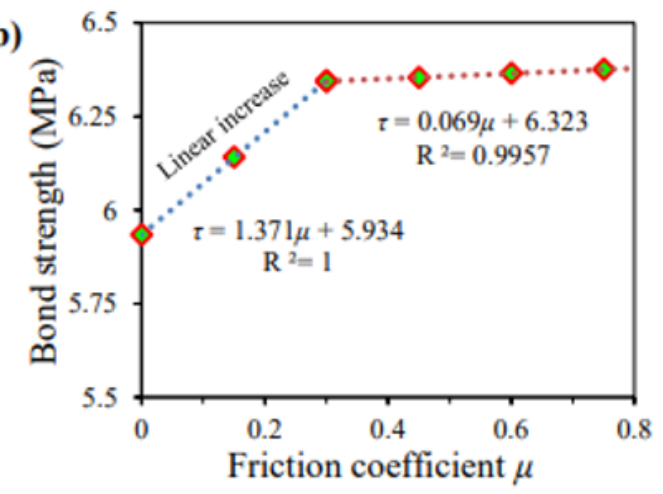

Figure 4. The effect of friction coefficient. (a) Bond stress-slip curve; (b) The ultimate bond strength.

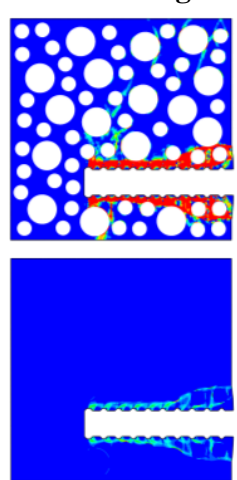

(a) $\mu=0$
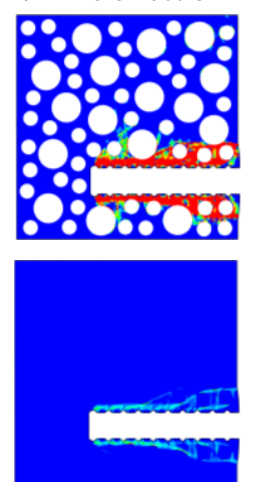

(b) $\mu=0.15$
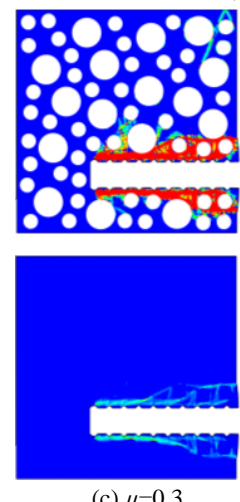

(c) $\mu=0.3$

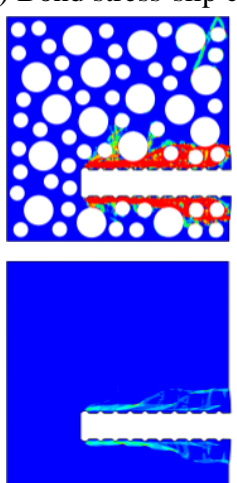

(d) $\mu=0.45$

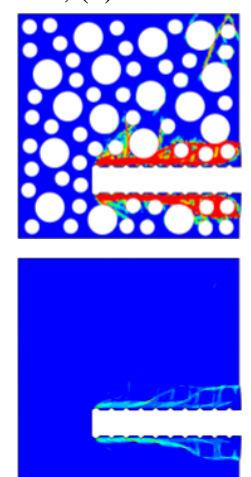

(e) $\mu=0.6$

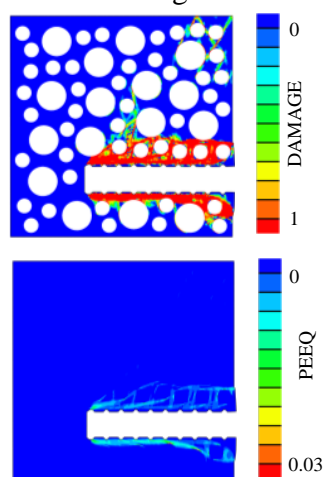

(f) $\mu=0.75$

Figure 5. Effect of coefficient of friction on the failure mode.

\section{Conclusions}

From the perspective of the mesoscale, considering the heterogeneity of the concrete material composition and frictional resistance and the mechanical interlocking between rebar and concrete, a mesoscale numerical analysis model and method for the study of the bond performance of ribbed reinforced concrete is established. Basis of the verification of the rationality of the mesoscopic model, the influence of friction coefficient on the failure mode and bond stress-slip curve is discussed. According to the numerical simulation results, the following conclusions can be drawn:

(1) The mesoscale model can simulate the bond performance of the steel-concrete interface and describe the localized effects of cracking of the concrete realistically.

(2) Cracking of concrete caused by relative slippage between steel and concrete has a strong localized effect, mainly due to the crushing and failure of the concrete in the local area in front of the ribbed steel bars.
(3) With the friction coefficient increases, the bond strength increases, but when the friction coefficient is greater than 0.3 , the bond strength increases little.

(4) The proportion of bond stress provided by friction is from $0 \%$ to $7 \%$ and the ratio of the friction force and mechanical force is from 0 to $7.5 \%$ when friction coefficient is from 0 to 0.75 .

\section{Acknowledgements}

This research was supported by the National Natural Science Foundation of China (No. 51822801, 51421005). The support is gratefully acknowledged.

\section{References}

1. Ma Y, Zhang J, Wang L and Liu Y 2013 Probabilistic prediction with Bayesian updating for strength degradation of RC bridge beams Struct. Saf. 44 102109 
2. Tondolo F 2015 Bond behaviour with reinforcement corrosion Constr. Build. Mater. 93 926-932

3. Melo J, Rossetto T and Varum H 2015 Experimental study of bond-slip in RC structural elements with plain bars Mater. Struct. 488 2367-2381

4. Haskett M, Oehlers D and Ali M 2008 Local and Global Bond Characteristics of Steel Reinforcing Bars Eng. Struct. 302 376-383

5. Shima H, Chou L and Okamura H 1987 Micro and macro models for bond in reinforced concrete J. Fac. Eng. 392 133-194

6. Xu Y 1997 Simplified Model for the Bond-slip Constitutive Relation of Reinforced Concrete Eng. Mech. A02 34-38 (in Chinese)

7. China Association for Engineering Construction Standardization 2010 Code for design of concrete structures 50010 (Beijing: China Planning Press) (in Chinese)

8. Wang X and Liu X 2004 Modeling bond strength of corroded reinforcement without stirrups Cem. Concr. Res. 348 1331-1339

9. Xu Y 1990 Experimental study of anchorage properties for deformed bars in concrete (Beijing: Tsinghua university press) (in Chinese)

10. Ngo D and Scordelis A 1967 Finite element analysis of reinforced concrete beams ACI. Struct. J. 64 152163

11. Richard B, Ragueneau F, Cremona C, Adélaide L and Tailhan J 2010 A three-dimensional steel/concrete interface model including corrosion effects Eng. Fract. Mech. 776 951-973

12. Rezazadeh M, Carvelli V and Veljkovic A 2017 Modelling bond of GFRP rebar and concrete Constr. Build. Mater. 153 102-116

13. Dehestani M and Mousavi S 2015 Modified steel bar model incorporating bond-slip effects for embedded element method Constr. Build. Mater. 81 284-290

14. Berra M, Castellani A, Coroneli D, Zanni S and Zhang G 2003 Steel-concrete bond deterioration due to corrosion: finite-element analysis for different confinement levels Mag. Concrete. Res. 553 237-247

15. Ma Y, Guo Z, Wang L and Zhang J 2017 Experimental investigation of corrosion effect on bond behavior between reinforcing bar and concrete Constr. Build. Mater. 152 240-249

16. Xu Y L, Shen W and Wang H 1994 An experimental study of bond-anchorage properties of bars in concrete J. Arch. Struct. 153 26-36

17. Huang Y, Yang Z, Chen X and Liu G 2016 Monte Carlo simulations of meso-scale dynamic compressive behavior of concrete based on X-ray computed tomography images Int. J. Impact. Eng. 97 $102-115$

18. Yan P, Zhang J, Fang Q, Zhang Y and Fan J 2016 3D numerical modelling of solid particles with randomness in shape considering convexity and concavity Powder. Technol. 301 131-140
19. Zheng J, Li C and Jones M 2003 Aggregate distribution in concrete with wall effect Mag. Concrete. Res. 553 257-265

20. Du X, Jin L and Ma G 2014 Numerical simulation of dynamic tensile-failure of concrete at meso-scale Int. J. Impact. Eng. 66 5-17

21. Lee J and Fenves G 1998 Plastic-damage model for cyclic loading of concrete structures ASCE. J. Eng. Mech. 1248 892-900 